Article

\title{
Pore Structure Evolution and Its Effect on Strength Development of Sulfate-Containing Cemented Paste Backfill
}

\author{
Hao Rong ${ }^{1,2}$, Min Zhou ${ }^{1,2}$ and Haobo Hou ${ }^{1,2, *}$ \\ 1 School of Resource and Environmental Science, Wuhan University, Wuhan 430079, China; \\ ronghao2363568@sina.com (R.H.); zhoumin@whu.edu.cn (M.Z.) \\ 2 Hubei Environmental Remediation Material Engineering Technology Research Center, Wuhan 430079, China \\ * Correspondence: hhb-bhh@163.com
}

Academic Editor: Abbas Taheri

Received: 1 December 2016; Accepted: 11 January 2017; Published: 17 January 2017

\begin{abstract}
In this study, the effects of the initial sulfate content on the properties of cemented paste backfill (CPB) made from coarse tailings has been investigated via mercury intrusion porosimetry. The combined effects of the sulfate content and curing time on the total porosity, pore size distribution, and unconfined compressive strength of the produced material were discussed. It was found that the specimens with an initial sulfate content of 5000 and 35,000 ppm exhibited higher unconfined compressive strength, while the resulting fine porous structures characterized by pore radii of 10-400 and 1-10 $\mu \mathrm{m}$ significantly improved the mechanical properties of the CPB. In addition, an increase in the curing time decreased the overall pore volume in the radius range of $1-400 \mu \mathrm{m}$ but increased the pore volume at pore radii less than $1 \mu \mathrm{m}$.
\end{abstract}

Keywords: sulfate attack; mercury porosimetry; pore size distribution; hydration products; compressive strength

\section{Introduction}

More than 150 different types of mineral products can be found near around 8000 mining plants and more than 12,000 tailing dams in China. The total amount of the produced tailings equals 10 billion tons, and their annual emission in China has exceeded 1 billion tons since 2009 [1,2]. Safe disposal of mine tailings is one of the major environmental problems in the world. The use of special dumping facilities (such as dams or ponds) represents a convenient disposal method; however, the formation of stockpiles on the ground surface can cause serious environmental pollution and ecological damage [3] as well as other problems such as tailing dam failures [4-6]. Therefore, the utilization of mine tailings for backfilling underground voids is a better way of disposing of these solid wastes. The main benefits of the backfilling technology are as follows: (1) providing a structural support for mining areas, thus creating a safe working environment; (2) minimizing surface subsidence; and (3) reducing the costs of tailing disposal and rehabilitation [7-9]. Hence, underground backfilling leads to harmless ground conditions inside the mines and improves their operational safety.

The use of cemented paste backfill (CPB) is one of the most popular techniques of tailing utilization around the world. In general, CPB represents a mixture of hydraulic binders, water, and dehydrated tailings produced during mine operation [10-12], and is commonly used for filling mined-out areas of underground mines due to its technological and economic advantages [13-15]. 
$\mathrm{CPB}$ mixtures often contain sulfate species. It is generally accepted that sulfate attacks negatively affect the strength and durability of cement-based products. Two main types of sulfate attack exist: (1) reaction of calcium aluminate (C3A) with sulfate ions, which produces ettringite species; and (2) reaction of calcium hydroxide $(\mathrm{CH})$ species with sulfate ions, which leads to the formation of gypsum [16]. Both these processes ultimately cause a significant volume expansion of the CPB material [13].

The presence of sulfate ions in $\mathrm{CPB}$ originates from the following four sources: sulfate minerals in the utilized tailings; air/sulfur dioxide blowing from mixture used for destruction of gold mines; gypsum or anhydrite species, which were added during clinker preparation; and mine processing water utilized during CPB preparation [17].

Fall and Pokharel [17] investigated the mechanical properties and microstructural parameters of $\mathrm{CPB}$ specimens with different initial sulfate contents at various curing times and temperatures. They reported that a sulfate content of $15,000 \mathrm{ppm}$ and curing temperatures of $20^{\circ} \mathrm{C}$ would contribute to the strength development of the samples during early and long-term curing times. However, CPBs with a sulfate content of up to 25,000 ppm usually show lower strength at all curing times. The reduction in unconfined compressive strength (UCS) values of CPB specimens was related to the inhibition of binder hydration at high sulfate contents. Ouellet et al. [18] examined the microstructural evolution of various CPB specimens prepared with ground silica by mercury intrusion porosimetry (MIP) tests. The results showed that a combination of mixing water containing sulfate (up to $7549 \mathrm{ppm}$ ) with the slag-based binder affords the highest UCS values and maximum percentage of fine pores. This observation can be attributed to the potential precipitation of sulfate phases in pores, which may have a beneficial effect on strength development. Fall and Benzaazoua [19] developed a mathematical model to analyze the cost and the strength development of CPB with different sulfate contents. The developed model indicated the relationship between the mechanical properties and the sulfate content of the paste backfill and predicted its strength for various curing ages. This study demonstrated that the strength of paste backfill strength is strongly influenced by the sulfate content. However, the reasons for extremely high initial sulfate contents ( $\geq 30,000 \mathrm{ppm})$ in the prepared CPB mixtures as well as the effects produced by the pore size distributions (PSDs) on their mechanical properties have not been investigated in detail.

Hence, the main objectives of this study are as below:

- investigation of the dependence of the resulting $\mathrm{CPB}$ strength on the initial range of the sulfate content;

- gaining a better understanding of the effects produced by the pores with different radii on the $\mathrm{CPB}$ mechanical properties;

- determination of the effects of the $\mathrm{CPB}$ curing time on the pore volume variations corresponding to different diameters.

\section{Materials and Methods}

\subsection{Materials}

A binder, ground silica, and distilled water solutions with different sulfate contents were used to prepare CPB samples in this study.

\subsubsection{Binder}

In accordance with the GB 175-2007 [20] Chinese standard, 32.5 composite Portland cement (CPC) with a specific gravity (Gc) of 2.9 was used as a binding agent (its major chemical components are listed in Table 1). 
Table 1. Major chemical components of the CPC binder.

\begin{tabular}{ccccccc}
\hline Component & $\mathrm{MgO}$ & $\mathrm{Al}_{2} \mathrm{O}_{3}$ & $\mathrm{SiO}_{2}$ & $\mathrm{SO}_{3}$ & $\mathrm{CaO}$ & $\mathrm{Fe}_{2} \mathrm{O}_{3}$ \\
\hline wt $\%$ & 5.00 & 11.00 & 26.94 & 5.25 & 47.66 & 1.34 \\
\hline
\end{tabular}

\subsubsection{Tailings}

Ground silica containing $99.7 \mathrm{wt} \%$ of $\mathrm{SiO}_{2}$ (silica tailings, ST) was used in all prepared CPB samples. According to the generally accepted classification of tailings in China [21], the utilized ST material containing $7.17 \mathrm{wt} \%$ of fine particles and $71.87 \mathrm{wt} \%$ of coarse particles can be characterized as coarse tailings (Table 2). The measurements of Gs of ground silica conducted in this study conformed to the GB/T 208-94 [22] Chinese standard. Different particle distributions in the used tailings were determined using a particle size analyzer (Microtrac S3500, Microtrac, Montgomeryville, PA, USA), while various chemical and physical parameters of the ST material are described in Table 3 and Figure 1. The equations utilized for estimating the ST curvature and uniformity coefficients $(\mathrm{Cc}$ and $\mathrm{Cu})$ are provided elsewhere [23].

Table 2. Generally accepted classifications for various tailings in China.

\begin{tabular}{ccccccc}
\hline Classification & \multicolumn{2}{c}{ Coarse } & \multicolumn{2}{c}{ Medium } & \multicolumn{2}{c}{ Fine } \\
\hline Diameter $(\mathrm{mm})$ & $>0.074$ & $<0.019$ & $>0.074$ & $<0.019$ & $>0.074$ & $<0.019$ \\
wt $\%$ & $>40$ & $<20$ & $20-40$ & $20-55$ & $<20$ & $>50$ \\
\hline
\end{tabular}

Table 3. Physical parameters of the utilized silica tailings (ST).

\begin{tabular}{ccccccccc}
\hline Element Unit & $\mathrm{D}_{\mathbf{1 0}}(\mu \mathrm{m})$ & $\mathrm{D}_{\mathbf{3 0}}(\mu \mathrm{m})$ & $\mathrm{D}_{\mathbf{5 0}}(\boldsymbol{\mu m})$ & $\mathrm{D}_{\mathbf{6 0}}(\mu \mathrm{m})$ & $\mathrm{D}_{\mathbf{9 0}}(\mu \mathrm{m})$ & $\mathrm{Gs}$ & $\mathrm{Cu}$ & $\mathrm{Cc}$ \\
\hline Value & 26.16 & 74.00 & 148.00 & 176.00 & 296.00 & 2.85 & 6.73 & 1.20 \\
\hline
\end{tabular}

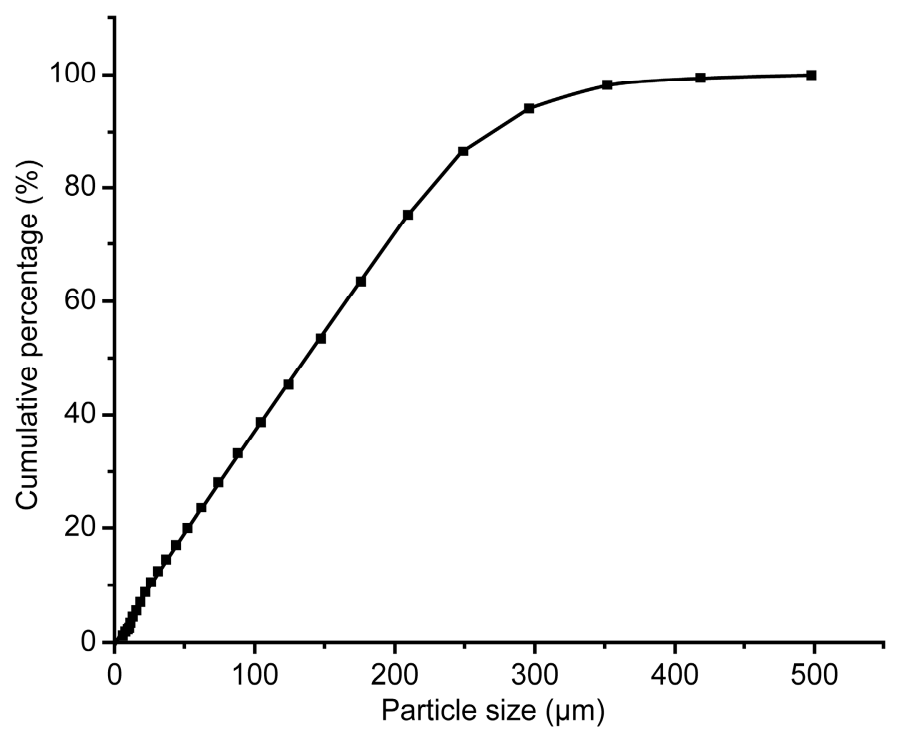

Figure 1. Particle size distributions obtained for the utilized ST.

\subsubsection{Mixing Water Solutions}

Distilled water was used to prepare mortar samples. Specified amounts of iron sulfate salt $\left(\mathrm{FeSO}_{4} \cdot 7 \mathrm{H}_{2} \mathrm{O}\right)$ were added to distilled water to prepare mixing water solutions with different contents of sulfate ions. 


\subsection{Preparation of Mortar Specimens}

Approximately 90 CPB mortar specimens were prepared using the specifications listed in Table 4 . In accordance with the GB/T 2419-2005 [24] Chinese standard, the flowability values determined for all tested mixtures exceeded $22 \mathrm{~cm}$. Afterwards, the obtained mixtures were poured into metal cubes with dimensions of $40.0 \mathrm{~mm} \times 40.0 \mathrm{~mm} \times 40.0 \mathrm{~mm}$. All samples were cured inside a closed cabinet at a temperature of $30 \pm 1{ }^{\circ} \mathrm{C}$ and relative humidity of $70 \%$ for periods of 7,14 , and 28 days. The obtained specimens were subjected to various mechanical tests and mercury intrusion porosimetry (MIP) studies.

Table 4. Mix proportions utilized for the cemented paste backfill (CPB) preparation (Tailings is ST, binder is CPC, percentage of binder dry weight is $10 \%$, water cement ratio is 3.33 ).

\begin{tabular}{cc}
\hline Name & FeSO $_{\mathbf{4}} \cdot \mathbf{7 \mathbf { H } _ { 2 }} \mathbf{O}(\mathbf{p p m})$ \\
\hline M-0 & 0 \\
M-5 & 5000 \\
M-10 & 10,000 \\
M-15 & 15,000 \\
M-20 & 20,000 \\
M-25 & 25,000 \\
M-30 & 30,000 \\
M-35 & 35,000 \\
M-40 & 40,000 \\
M-45 & 45,000 \\
\hline
\end{tabular}

\subsection{Testing Conditions}

Before conducting MIP tests, all specimens were dried to a constant mass inside a vacuum oven at a temperature of $50{ }^{\circ} \mathrm{C}$.

Mechanical tests were conducted in accordance with the JGJ/T 70 [25] Chinese standard. Each experiment was repeated three times, and the unconfined compressive strength (UCS) was determined for each specimen by averaging the experimental values obtained during three subsequent trials. MIP testing was performed using an Autopore instrument (IV 9500, Micromeritics, Atlanta, GA, USA).

\section{Results and Discussion}

\subsection{Effects of Curing Age on Strength Development and Total Porosity of CPB Specimens}

Figure 2 shows the strength development observed for the studied CPB specimens with different sulfate contents after 7,14 , and 28 days of aging. The obtained results indicate that the curing time significantly affects the development of the UCS regardless of the initial sulfate content. As the curing time increases, the UCS of the mortar specimens increases as well due to the formation of additional cement hydration products (such as calcium silicate hydrate and ettringite) inside the pores. Figure 2 also shows that the M-5 and M-35 specimens exhibited higher UCS values regardless of the curing time, while the magnitudes obtained for M-35 were systematically higher than those obtained for M- 5 , indicating that initial sulfate contents of 5000 and 35,000 ppm most strongly contributed to the strength development of the CPB specimens during early curing stages.

It has been reported that free calcium ions produced by the dissolution of unstable aluminate $\left(\mathrm{C}_{3} \mathrm{~A}\right)$ and calcium portlandite $\left(\mathrm{Ca}(\mathrm{OH})_{2}\right)$ reacts with sulphate existing in mixing water, thus increasing the precipitation of secondary expansive gypsum $\left(\mathrm{CaSO}_{4} \cdot 2 \mathrm{H}_{2} \mathrm{O}\right)$ and highly expansive ettringite $\left(3 \mathrm{CaO} \cdot \mathrm{Al}_{2} \mathrm{O}_{3} \cdot 3 \mathrm{CaSO}_{4} \cdot 32 \mathrm{H}_{2} \mathrm{O}\right)$. These reaction products generate high internal pressure, thereby damaging the strength of the $\mathrm{CPB}$ specimens $[17,19,26-30]$. 
The total porosity of the five representative mortar specimens is described in Figure 3. It can be concluded that the longer is the curing period, the larger is the yield of the cement hydration products. The filling effect observed for the hydration products resulted in a reduction of the total material porosity. Thus, the curing time and total porosity of the produced $\mathrm{CPB}$ specimens are highly correlated, owing to the continuous reaction between the binder and the water species (similar results were obtained in previous studies $[31,32])$. The UCS values can be strongly influenced by the total porosity, but determining the total porosity is not sufficiently assessing the mechanical strength at a certain curing age. The mortar samples M-20 and M- 45 are characterized by smaller total porosities and UCS values as compared to those obtained for M- 0 after 7 days of aging. On the other hand, M- 5 and M-35 have smaller total porosities and higher UCS values than M-0 does after 7 days of aging. The UCS value also is related with other factors, such as the amount of the cement and chemical composition of the mixtures [19].

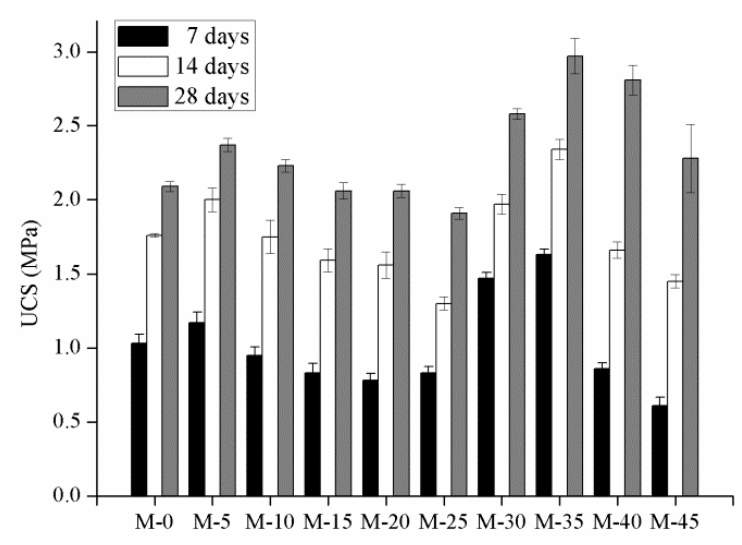

Figure 2. Unconfined compressive strength (UCS) values obtained for the studied mortar specimens (Error bars represent standard deviation).

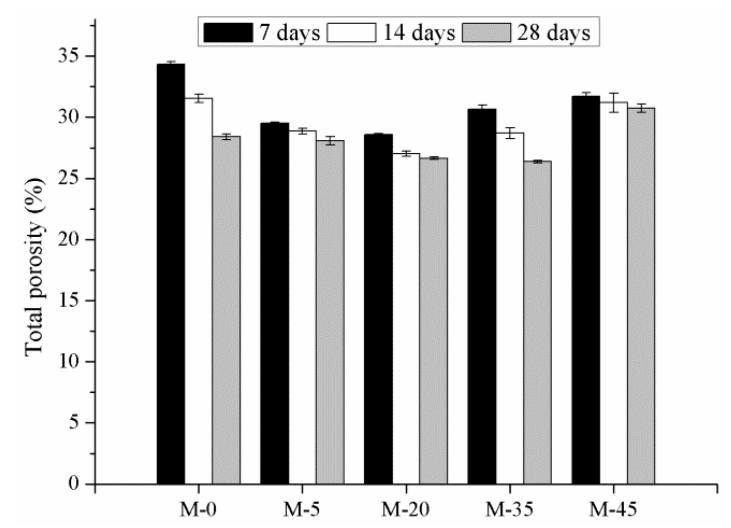

Figure 3. Total porosity values obtained for the studied mortar specimens (Error bars represent standard deviation).

\subsection{Pore Evolution and Effects of PSDs on UCS}

The PSDs obtained for the studied CPB mortar specimens as functions of the pore diameter are shown in Figure 4. Four different peaks were clearly observed after MIP testing, while more than one PSD peak was detected during similar studies by other researchers [33-35]. In this section, the properties of five representative samples evaluated after two different curing periods are discussed. 
The following four characteristic ranges of pore sizes with corresponding distribution peaks were observed: 10-400 $\mu \mathrm{m}$ (R1), 1-10 $\mu \mathrm{m}$ (R2), 0.1-1 $\mu \mathrm{m}$ (R3), and $<0.1 \mu \mathrm{m}$ (R4). After 7 days of curing, samples M-5 and M-35 with higher UCS values exhibited finer porous structures in the R1 and $\mathrm{R} 2$ regions (as compared to the other specimens). The porosity of sample M-5 is lower than that of samples M-0 and M-20 in the R1 and R2 regions and that the porosity of M-35 is lower than that of samples M-20 and M-45 in the R1 and R2 regions. However, after 28 days of curing, sample M-5 was characterized by less pores in the R1 and R2 regions, while sample M-35 exhibited an opposite trend. Sample M- 5 has less pores than samples M- 0 and M-20 in the R1 and R2 regions, while sample M-35 has more pores than samples M-20 and M-45 in the R1 and R2 regions. At the same time, the observed relationship between the UCS and the pore volume in the R3 and R4 regions was ambiguous.

The evolution of the $\mathrm{CPB}$ porous structure in the specified four pore size regions with curing time is described in Figure 5. After increasing the curing time, the pore volumes measured in the R1 and R2 regions decreased, while the pore volumes determined in the R3 and R4 regions increased (except for the M-35 specimen). Hence, it can be concluded that the finer pore structures with radii of $10-400 \mu \mathrm{m}$ (R1) and 1-10 $\mu \mathrm{m}$ (R2) enhanced the mechanical properties of the mortar specimens, while the effects of the pores with radii of $0.1-1 \mu \mathrm{m}(\mathrm{R} 3)$ and $<0.1 \mu \mathrm{m}$ (R4) on the material strength were insignificant at the specified curing times. The observed phenomenon can be possibly explained by the ability of the coarser pore structures (corresponding to the pore radii of $10-400 \mu \mathrm{m}$ and 1-10 $\mu \mathrm{m}$ ) to produce microcracks inside the hardened samples.
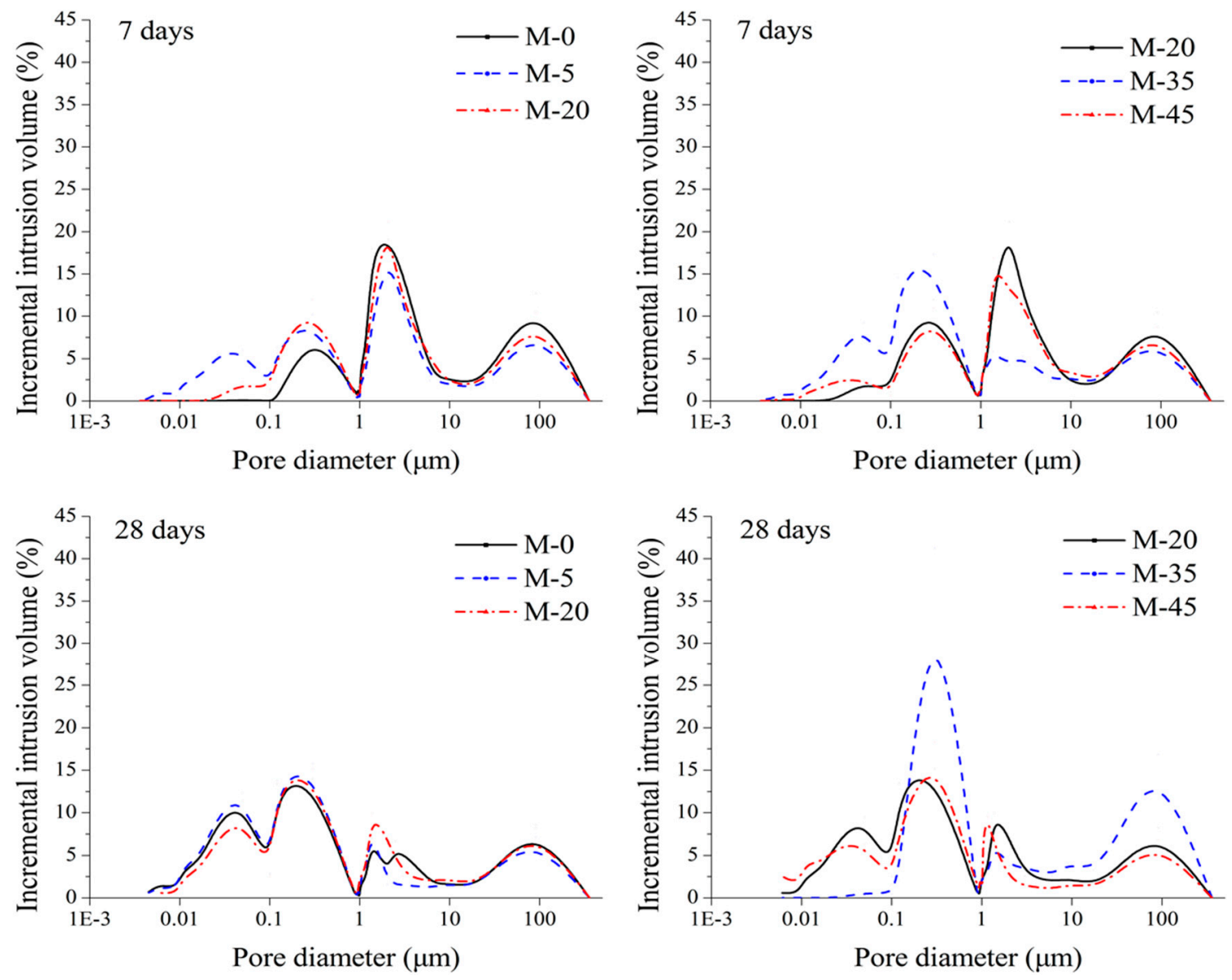

Figure 4. Pore size distributions (PSDs) obtained for the prepared mortar specimens after 7 and 28 days of aging. 


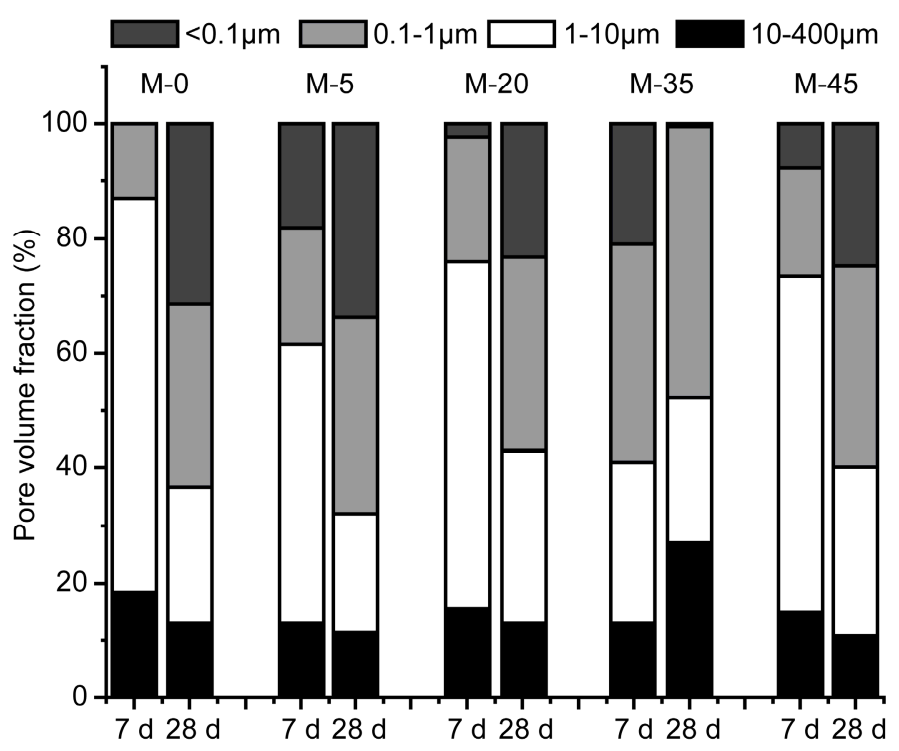

Figure 5. Evolution of the pore volume fractions observed for the aged CPB specimens.

\section{Conclusions}

In this study, the development of the CPB porous structure and its physical properties were discussed, and the relationship between the corresponding PCD and UCS parameters has been analyzed. The obtained experimental and analytical results led to the following conclusions:

- The UCS of the studied mortar samples increased, while their total porosity decreased with an increase in the curing time regardless of the initial sulfate content. The sulfate contents in the CPB specimens equal to 5000 and 35,000 ppm most strongly contributed to their strength development during early curing stages.

- The UCS values can be strongly influenced by the total porosity, but simply determining the total porosity does not sufficiently assess the mechanical strength at a certain curing age. The UCS value also is also related with other factors, such as the amount of the cement and the chemical composition of the mixtures.

- The observed effects of the PSDs on the specimen mechanical properties varied with pore radii. The structures characterized by smaller pore volumes with radii of 1-10 $\mu \mathrm{m}$ and 10-400 $\mu \mathrm{m}$ exhibited higher UCS values.

- An increase in the curing time generally decreased the pore volume of the specimens with pore radii of $10-400 \mu \mathrm{m}$ and $1-10 \mu \mathrm{m}$ but increased the pore volume for the specimens with pore radii of $0.1-1 \mu \mathrm{m}$ and $<0.1 \mu \mathrm{m}$ (except for M-35).

- Future studies are aimed at investigating the resistance of $\mathrm{CPB}$ produced from sulfate-rich mixing water to sulfate attack over a curing period of 180/360 days (long-term performance).

Acknowledgments: This work was supported by the National Science \& Technology Pillar Program, China (No. 2015BAB01B03).

Author Contributions: H.R. and H.H. conceived and designed the experiments; H.R. performed the experiments; H.R. and M.Z. analyzed the data; M.Z. contributed analysis tools; H.R. wrote the paper.

Conflicts of Interest: The authors declare no conflict of interest. 


\section{References}

1. Huang, J.Z.; Wang, J.W. China Association of Resource Comprehensive Utilization. Development Report on Bulk Industrial Solid Waste Comprehensive Utilization; Light Industry Press: Beijing, China, 2009.

2. Zhang, S.; Xue, X.; Liu, X.; Duan, P.; Yang, H.; Jiang, T.; Wang, D.; Liu, R. Current situation and comprehensive utilization of iron ore tailing resources. J. Min. Sci. 2006, 42, 403-408. [CrossRef]

3. Sivakugan, N.; Rankine, R.M.; Rankine, K.J.; Rankin, K.S. Geotechnical considerations in mine backfilling in australia. J. Clean. Prod. 2006, 14, 1168-1175. [CrossRef]

4. Passariello, B.; Giuliano, V.; Quaresima, S.; Barbaro, M.; Caroli, S.; Forte, G.; Carelli, G.; Iavicoli, I. Evaluation of the environmental contamination at an abandoned mining site. Microchem. J. 2002, 73, 245-250. [CrossRef]

5. Licskó, I.; Lois, L.; Szebényi, G. Tailings as a source of environmental pollution. Water Sci. Technol. 1999, 39, 333-336. [CrossRef]

6. Yi, Z.L.; Sun, H.H.; Wei, X.Q.; Li, C. Iron ore tailings used for the preparation of cementitious material by compound thermal activation. Int. J. Miner. Metall. Mater. 2009, 16, 355-358. [CrossRef]

7. Fridjonsson, E.O.; Hasan, A.; Fourie, A.B.; Johns, M.L. Pore structure in a gold mine cemented paste backfill. Miner. Eng. 2013, 53, 144-151. [CrossRef]

8. Yilmaz, E.; Kesimal, A.; Ercikdi, B. Evaluation of acid producing sulphidic mine tailings as a paste backfill. Turk. J. Earth Sci. Rev. 2004, 17, 11-19.

9. Berzaazoua, M.; Ouellet, J.; Servant, S.; Newman, P.; Verburg, R. Cementitious backfill with high sulfur content: Physical, chemical and mineralogical characterization. Cem. Concr. Res. 1999, 29, 719-725. [CrossRef]

10. Benzaazoua, M.; Fall, M.; Belem, T. A contribution to understanding the hardening process of cemented pastefill. Miner. Eng. 2004, 17, 141-152. [CrossRef]

11. Kesimal, A.; Ercikdi, B.; Yilmaz, E. The effect of desliming by sedimentation on paste backfill performance. Miner. Eng. 2003, 16, 1009-1011. [CrossRef]

12. Orejarena, L.; Fall, M. Artificial neural network based modeling of the coupled effect of sulphate and temperature on the strength of cemented paste backfill. Can. J. Civ. Eng. 2011, 38, 100-109. [CrossRef]

13. Ercikdi, B.; Cihangir, F.; Kesimal, A.; Deveci, H.; Alp, I. Utilization of industrial waste products as pozzolanic material in cemented paste backfill of high sulphide mill tailings. J. Hazard. Mater. 2009, 168, 848-856. [CrossRef] [PubMed]

14. Fall, M.; Célestin, J.C.; Pokharel, M.; Toure, M. Contribution to understanding the effects of curing temperature on the mechanical properties of mine cemented tailings backfill. Eng. Geol. 2010, 114, 397-413. [CrossRef]

15. Ercikdi, B.; Baki, H.; Izki, M. Effect of desliming of sulphide-rich mill tailings on the long-term strength of cemented paste backfill. J. Environ. Manag. 2013, 115, 5-13. [CrossRef] [PubMed]

16. Bing, B.; Cohen, M.D. Does gypsum formation during sulphate attack on concrete lead to expansion? Cem. Concr. Res. 2000, 30, 117-123.

17. Fall, M.; Pokharel, M. Coupled effects of sulphate and temperature on the strength development of cemented tailings backfills: Portland cement-paste backfill. Cem. Concr. Compos. 2010, 32, 819-828. [CrossRef]

18. Ouellet, S.; Bussière, B.; Aubertin, M.; Benzaazoua, M. Microstructural evolution of cemented paste backfill: Mercury intrusion porosimetry test results. Cem. Concr. Res. 2007, 37, 1654-1665.

19. Fall, M.; Benzaazoua, M. Modeling the effect of sulphate on strength development of paste backfill and binder mixture optimization. Cem. Concr. Res. 2005, 35, 301-314. [CrossRef]

20. Common Potland Cement; Chinese Standard: GB/T 175-2007; China Building Material Federation: Beijing, China, 2007.

21. Sun, H.H.; Huang, Y.C.; Yang, B.G. Contemporary Cemented Backfill Technology; Metallurgical Industry Press: Beijing, China, 2002.

22. Standard Test for Cement Density; Chinese Standard: GB/T 208-1994; China National Building Material Group Co. Ltd.: Beijing, China, 1994.

23. Ke, X.; Hou, H.; Zhou, M.; Wang, Y.; Zhou, X. Effect of particle gradation on properties of fresh and hardened cemented paste backfill. Constr. Build. Mater. 2015, 96, 378-382. [CrossRef]

24. Test Method for Fluidity of Cement Mortar; Chinese Standard: GB/T 2419-2005; China Building Material Federation: Beijing, China, 2005. 
25. Standard for Test Method of Performance on Building Mortar; Chinese Standard: JGJ/T 70-2009; China Architecture \& Building Press: Beijing, China, 2009.

26. Hassani, F.P.; Ouellet, J.; Hossein, M. Strength development in underground high sulphate paste backfill operation. CIM Bull. 2001, 94, 57-62.

27. Kesimal, A.; Yilmaz, E.; Ercikdi, B. Evaluation of paste backfill test results obtained from different size slumps with varying cement contents for sulphure rich mill tailings. Cem. Concr. Res. 2004, 34, 1817-1822. [CrossRef]

28. Tariq, A.; Nehdi, M. Developing durable paste backfill from sulphidic tailings. Waste Res. Manag. 2007, 160, 155-166. [CrossRef]

29. Cihangir, F.; Ercikdi, B.; Kesimal, A.; Turan, A.; Deveci, H. Utilisation of alkali-activated blast furnace slag in paste backfill of high-sulphide mill tailings: Effect of binder type and dosage. Miner. Eng. 2012, 30, $33-43$. [CrossRef]

30. Ercikdi, B.; Külekci, G.; Yilmaz, T. Utilization of granulated marble wastes and waste wricks as mineral admixture in cemented paste backfill of sulphide-rich tailings. Constr. Build. Mater. 2015, 93, 573-583.

31. Yu, Z.; Ye, G. The pore structure of cement paste blended with fly ash. Constr. Build. Mater. 2013, 45, 30-35. [CrossRef]

32. Jiang, L.; Guan, Y. Pore structure and its effect on strength of high-volume fly ash paste. Cem. Concr. Res. 1999, 29, 631-633. [CrossRef]

33. Li, K.; Zeng, Q.; Luo, M.; Pang, X. Effect of self-desiccation on the pore structure of paste and mortar incorporating 70\% GGBS. Constr. Build. Mater. 2014, 51, 329-337. [CrossRef]

34. Cook, R.A.; Hover, K.C. Mercury porosimetry of hardened cement paste. Cem. Concr. Res. 1999, 31, $933-943$. [CrossRef]

35. Silva, D.A.; John, V.M.; Ribeiro, J.L.D.; Roman, H.R. Pore size distribution of hydrated cement pastes modified with polymers. Cem. Concr. Res. 2001, 31, 1177-1184. [CrossRef]

(C) 2017 by the authors; licensee MDPI, Basel, Switzerland. This article is an open access article distributed under the terms and conditions of the Creative Commons Attribution (CC-BY) license (http://creativecommons.org/licenses/by/4.0/). 